\title{
Null mutation of mCOUP-TFI results in defects in morphogenesis of the glossopharyngal ganglion, axonal projection, and arborization
}

\author{
Yuhong Qiu, ${ }^{1,2}$ Fred A. Pereira, ${ }^{1,2}$ Francesco J. DeMayo, ${ }^{1}$ John P. Lydon, ${ }^{1}$ Sophia Y. Tsai, ${ }^{1,3}$ and \\ MingJer Tsai $1,3,4$ \\ ${ }^{1}$ Department of Cell Biology, and ${ }^{4}$ M edicine, Baylor College of Medicine, Houston, Texas 77030 USA
}

The COUP-TFs are orphan members of the steroid/thyroid hormone receptor superfamily. Multiple COUP-TF members have been cloned and they share a high degree of sequence homology between species as divergent as D rosophila and humans, suggesting a conservation of function through evolution. The COUP-TFs are highly expressed in the developing nervous systems of several species examined, indicating their possible invol vement in neuronal development and differentiation. In the mouse, there are two very homologous COUP-TF genes (I and II) and their expression pattems overlap extensively. To study the physiological function of mCOUP-TFI, a genetargeting approach was undertaken. We report here that mCOUP-TFI null animals die perinataly. Mutant embryos display an altered morphogenesis of the ninth cranial ganglion and nerve. The aberrant formation of the ninth ganglion is most possibly attributable to extra cell death in the neuronal precursor cell population. In addition, at midgestation, aberrant nerve projection and arborization were oberved in several other regions of mutant embryos. These results indicate that mCOUP-TFI is required for proper fetal development and is essential for postnatal development. Furthermore, mCOUP-TFI possesses vital physiological functions that are distinct from mCOUP-TFII despite of their high degree of homology and extensive overlapping expression patterns.

[Key Words: COUP-TF; glossopharyngeal ganglion; axonal projection; arborization]

Received May 6, 1997; revised version accepted June 17, 1997.

COUP-TF (chicken ovalbumin upstream promoter-transcription factor) is one of the most characterized orphan receptors of the steroid/thyroid hormone receptor superfamily. Two COUP-TF genes were cloned initially from human cells, named hCOUP-TFI (Wang et al. 1989; EAR3, M iyajima et al. 1988) and hCOUP-TFIl (Ritchie et al. 1990; Wang et al. 1991; ARP-1, Ladias and Karathanasis 1991). Since the initial cloning, the COUP-TF subfamily has expanded rapidly. Homologs have been cloned from many species, from Drosophila to mouse (for review, see Qiu et al. 1994b; T sai and T sai 1997 and the references therein). Most of the species examined have more than one COUP-TF homolog. In addition, COUP-TF subfamily members share a high degree of homology within and between species (Qiu et al. 1994b; Tsai and Tsai 1997), implying that they may serve conserved functions. However, despite extensive studies, the physiological function of COUP-TFs remains unknown.

\footnotetext{
${ }^{2}$ These authors contributed equally to this work. ${ }^{3}$ These authors contributed equally to this work. ${ }^{4}$ Corresponding author.

E-MAIL mtsai @bmc.tmc.edu; FAX (713) 798-8227.
}

It has been demonstrated that COUP-TFs bind to AGGTCA direct repeats with various spacings, which include the response elements for the retinoic acid receptors (RAR), retinoid $X$ receptors $(R X R)$, vitamin $D_{3}$ re ceptor (VDR), and thyroid hormone receptors (TR) (Cooney et al. 1992). When cotransfected, COUP-TFs can inhibit the activation function of the above menti oned receptors in the presence of their cognate ligands. COUP-TFs exert their inhibitory activity mainly by competitive DNA binding of the common response ele ments and by heterodimerizing with the common partner RXR (Cooney et al. 1992 1993; Kliewer et al. 1992a; Tran et al. 1992; Leng et al. 1996). Therefore, COUP-TFs are proposed to modulate vitamin $D_{3}$, the thyroid hormone, and the RA signaling pathways. In addition, COUP-TFs have been shown to regulate negatively the expression of many genes by competing for the same or overlapping response elements with other positive regulators (for review, see Qiu et al. 1994b; Tsai and Tsai 1997). For instance, COU P-TFs could regulate negatively the expression of several apolipoproteins by antagonizing the positive regulator hepatocytenuclear factor 4 (HNF-4) (Ladias and Karathanasis 1991; Ladias et al. 
1992; Mietus-Snyder et al. 1992). Thus, COUP-TFs may also function independently of the above mentioned signaling pathways.

In Drosophila, mutation of the COUP-TF homolog, the seven-up gene (svp), is lethal. M osaic analysis demonstrated that svp activity is required for photoreceptor cell fate determination as loss-of-function mutations in svp transforms the fate of these photoreceptor cells into another photoreceptor cell, the R7 cell (Mlodzik et al. 1990). In zebrafish, Xenopus, chick, and mouse, COUPTFs are expressed at high levels in the developing central nervous system, suggesting that they are involved in neurogenesis (Tsai and Tsai 1997 and the references therein). In mouse, COUP-TFs are al so highly expressed in many developing organs and the expression level decreases with completion of differentiation, suggesting that COUP-TFs may also be involved in organogenesis (Jonk et al. 1994; Pereira et al. 1994). Collectively, this evidence suggests that COUP-TFs play conserved and vital roles during embryonic development.

To assess the physiological function of COUP-TFs in vivo, we proceeded to disrupt one of the two mouse COUP-TF genes (mCOUP-TFI) by homologous recombination. MCOUP-TFI and mCOUP-TFII share an exceptional degree of homology at the amino acid level $(99 \%$ identity in the DNA-binding domain and $96 \%$ identity in the putative ligand-binding domain) (Qiu et al. 1994a; Tsai and Tsai 1997). Furthermore, their expression patterns overlap extensively (Qi iu et al. 1994a; T sai and Tsai 1997), suggesting that they might serve redundant functions. We report here that the mCOUP-TFI null mutant dies perinataly apparently from starvation and dehydration. Homozygous mutant animals exhibit defects in morphogenesis of the ninth cranial ganglion and nerve. This results in fewer neurons in the mutant ganglia and abnormal nerve projections toward the hindbrain. This defective ganglion formation probably resulted from an excess cell death in the ganglionic precursor cells. In addition, axonal guidance defects were observed in several regions of the mutant embryos. Our results clearly demonstrate that mCOUP-TFI is important for proper development of the peripheral nervous system and that mCOUP-TFI serves a vital function that is not shared by mCOUP-TFII.

\section{Results}

\section{Targeted disruption of the MCOUP-TFI gene}

A genomic clone isolated from a mouse 129Sv genomic library was used to construct the targeting vector. This clone contained the entire mCOUP-TFI gene, which spans three exons. The amino-terminal and the DNAbinding domain are in the first exon, whereas the ligandbinding domain is split into two exons (Qiu et al. 1995). The targeting vector contains a $0.7-\mathrm{kb} 5^{\prime}$ homologous sequence and a $6.5-\mathrm{kb} 3^{\prime}$ homologous sequence flanking the neo ${ }^{r}$ cassette (Fig. 1A). A 4.0-kb genomic region including the amino-terminus and the entire DNA-binding domain and two-thirds of the ligand-binding domain will be del eted and replaced with the PGK-neobpA gene with correct recombination. This ensures that the mutation does not generate a functional protein with dominantnegative activity.

The targeting vector was linearized, electroporated into the AB1 embryonic stem (ES) cells, and subjected to positive (G418) and negative (FIAU) selections. A total of 850 colonies were screened by Southern bl ot analysis. The restriction enzyme $X$ bal was used as the diagnostic enzyme and a 0.5-kb Xbal-EcoRI fragment just upstream of the $5^{\prime}$ homologous sequence was used as probe. In the case of the wild-type mCOUP-TFI locus, an 8.0-kb fragment was generated, whereas in the mutant all ele, a 2.6$\mathrm{kb}$ fragment was produced because an extra Xbal site is introduced by the neo ${ }^{r}$ cassette (not shown). By using this strategy, 13 positive clones were obtained. To ensure that proper recombination had occurred on both the $5^{\prime}$ and $3^{\prime}$ ends of the neo ${ }^{r}$ cassette, another diagnostic enzyme (Sacl) was used and hybridized with the same probe. A 1.6-kb band and a 3.0-kb band were generated from the wild type and mutant allele, respectively (Fig. 1B). In addition, a 1.0-kb Pstl fragment, which resides downstream of the $3^{\prime}$ homologous sequence, was used as a probe on BamHI-digested samples. As expected, 8.0and $15-\mathrm{kb}$ bands were detected from wild-type and mutant alleles, respectively (Fig. 1B). Southern blots were stripped and reprobed with a fragment of the neo ${ }^{r}$ gene to ensure that there were no other insertions in the genome (not shown).

The ES cells carrying the mutated mCOUP-TFI locus were injected into C57BL/ 6 blastocysts. Two male chimeras with $100 \%$ agouti coat col or generated from one ES clone were mated to C57BL/ 6 females. Germ-line transmission was obtained, and the resulting heterozygous mice appeared phenotypically normal and were fertile. Heterozygous mice were intercrossed to generate homozygotes. To ensure no normal mCOUP-TFI transcript was generated from the mutated al lele, total RNA was isolated from embryonic day 13.5 (E13.5) embryos from heterozygote intercrosses. A 700-bp Sacl fragment containing the $3^{\prime}$ untranslated region of mCOUP-TFI gene was used as a probe in Northern hybridization analysis. As shown in Figure $1 C$, no mCOUP-TFI specific transcripts were detected in the homozygotes.

To define the physiological consequences of removing mCOUP-TFI in vivo, $F_{1}$ heterozygous mice were intercrossed to generate homozygotes. Homozygotes were not recovered at the weaning stage ( 3 weeks after birth) during initial analysis of $100 \mathrm{~F}_{2}$ offspring. However, a normal number of mutant pups were recovered at birth (newborn), in accordance with Mendelian inheritance (Table 1), indicating that the homozygotes survive until birth. Within the first 2 days after birth, an unusual number of newborn deaths were noticed. Dead pups were genotyped and the vast majority of them were found to be homozygotes (T able 1). A cl oser examination showed that homozygotes were indistinguishable from their wild-type or heterozygous littermates at birth. However, within hours after birth, the homozygotes became easily identifiable because of the lack or minimal milk in their stomachs. Almost all homozygotes died 


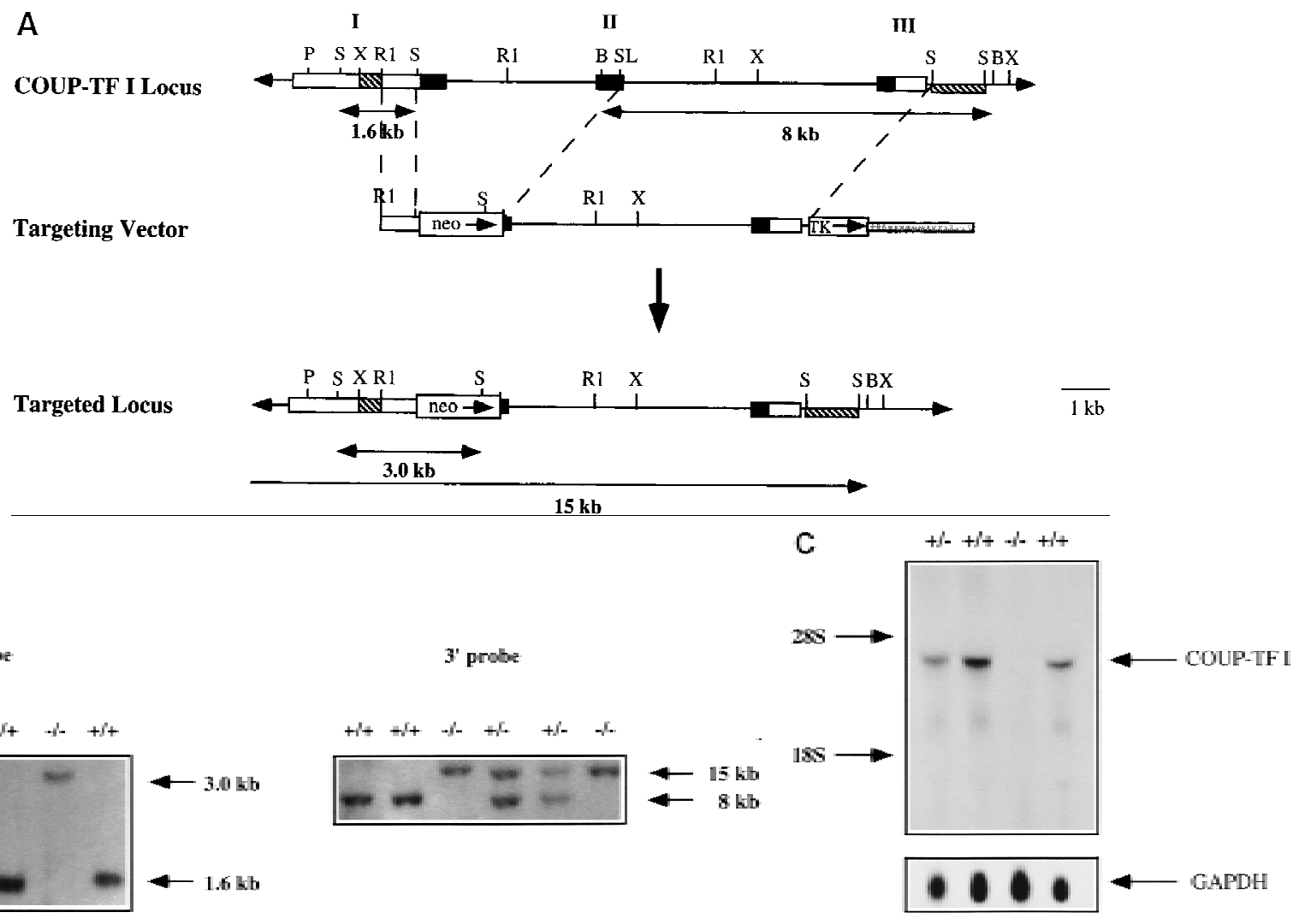

B

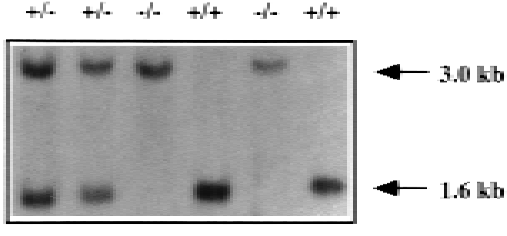

Figure 1. Targeted disruption of the mCOUP-TFI locus. (A) Targeting strategy. The mCOUP-TFI locus is shown on top with exons I-III in boxes. The solid region represents open reading frame and open boxes represents the $5^{\prime}$ - and $3^{\prime}$-untranslated regions. The hatched regions represent probes used in Southern bl ot analysis. The replacement vector includes a PGK-neo gene and a tk gene. The directions of transcription are indicated by arrows. The shaded box represents pBluescript vector. The left and right arms are indicated by dashed lines. The Sacl site at the right end of the left arm was destroyed during subcloning. The correctly recombined locus is shown at the bottom. Restriction sites are indicated above the lines. (P) Pstl; (S) Smal; (X) Xbal; (R1) EcoRI; (B) BamHI; (SL) Sall. (B) Southern blot analysis on a representative litter from a mCOUP-TFI heterozygote intercross. Genomic DN A was digested with Sacl and hybridized with the $5^{\prime}$ probe. A $1.6-\mathrm{kb}$ and a 3.0-kb band were generated from wild type and mutant all el es, respectively. For the $3^{\prime}$ probe, BamHI was used. The 8-kb and the 15-kb fragments were generated from the wild type and mutant allele, respectively. (C) N orthern analysis of RN A from E13.5 wildtype $(+/+)$, heterozygote $(+/-)$, and homozygote embryos $(-l-)$. A 700-bp Pstl-Scal fragment mainly containing the $3^{\prime}$ untranslated region of mCOUP-TFI was used as the probe. $N$ ote the absence of mCOUP-TFI mRNA in the homozygote. GAPDH was used as an internal control and is shown at bottom.

between 8 and $36 \mathrm{hr}$ after birth. After screening 901 offspring from heterozygote matings, two homozygotes were found to survive for 3 weeks, but they were very small, about one-quarter the size of their littermates, and appeared ataxic.

The mCOUP-TFI null exhibit defects in formation of the glossopharyngeal nerve

Anatomical analyses did not reveal any obvious structural defects in the craniofacial region that would have compromised the suckling process. Thus, given the extensive neuronal expression of mCOUP-TFI, the nervous system of the null mutants was examined. A monoclonal antibody $(2 \mathrm{H} 3)$ raised against the $165-k D$ neurofilament protein was used in whole-mount immunohistochemical analyses to examine the peripheral nervous system (Dodd et al. 1988). Thirty-seven embryos from
E9.5 to E11.5 (25-45 somites) were stained, of which 15 were wild type and 22 were mutant. The phenotype with

Table 1. Genotypes of offspring of COU P-TFI heterozygote matings

\begin{tabular}{lcccc}
\hline & Total & $H+$ & $H-$ & $-1-$ \\
\hline Adult $^{\mathrm{a}}$ & 901 & 318 & 581 & 2 \\
& $(100 \%)$ & $(35.3 \%)$ & $(64.5 \%)$ & $(0.2 \%)$ \\
N ewborns $^{\mathrm{b}}$ & 172 & 49 & 73 & 50 \\
& $(100 \%)$ & $(28.5 \%)$ & $(42.4 \%)$ & $(29.1 \%)$ \\
Perinatally dead $^{c}$ & 38 & 3 & 0 & 35 \\
\hline
\end{tabular}

Numbers represent individual animals and numbers in the brackets are percentage of specific genotypes determined. aThe mice were genotyped at wearning (21 days). ${ }^{b} \mathrm{~N}$ ewborns were collected between 4 and $8 \mathrm{hr}$ postnatal. 'Found dead within $36 \mathrm{hr}$ postnatal. 
the highest penetrance was an abnormality of the glossopharyngeal ganglion (IX) and its nerve. In wild-type embryos, ganglion IX and $X$ are well separated with very few nerve fiber connections between the two ganglionic masses. Multiple axonal projections between the glossopharyngeal ganglion and the hindbrain are readily seen in wild types (arrows in Fig. 2A,C). However, in mutants, ganglion IX appeared as an isol ated mass of neurons (arrowhead in Fig. 2B), or in other cases, a complete fusion or shunt of the axons away from the hindbrain and toward gangl ion $X$ (arrowhead in Fig. 2D). Indeed, embryos with a compl ete fusion of gangl ia IX and $X$ had no axonal fibers from ganglion IX projecting to the hindbrain. Of 22 mutant embryos examined, only one embryo exhibited wild-type-like appearances for the glossopharyngeal nerve, presumably attributable to incomplete penetrance. The defect in the gl ossopharyngeal gangli on was commonly seen on a single side of a given embryo, with the other side appearing phenotypically wild type. However, in the more severely affected mutants, both sides showed defects (one example is shown in Fig. 8B,C,E,F,

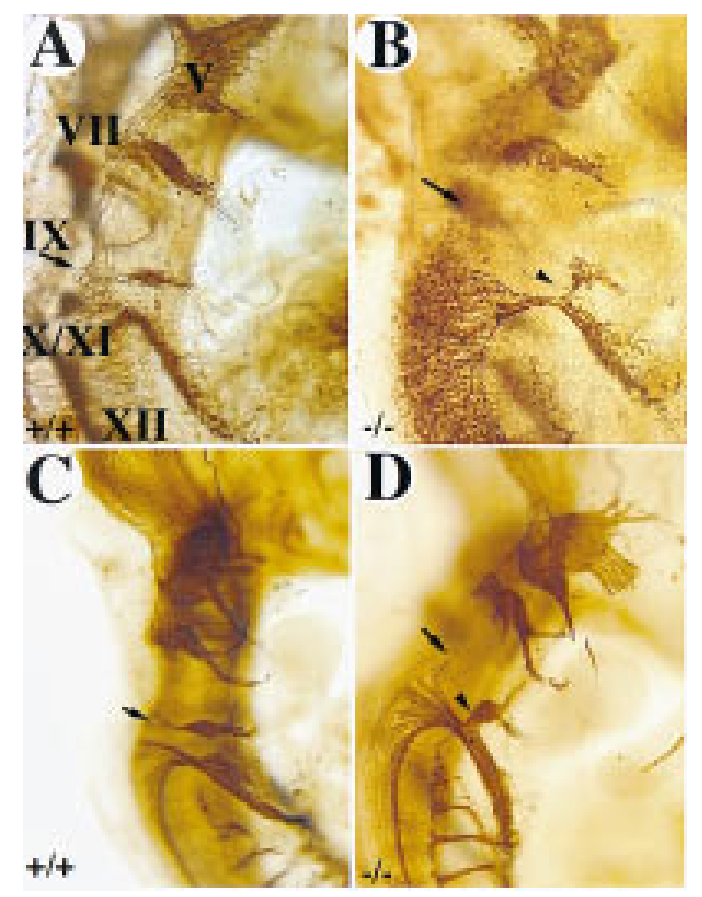

Figure 2. Whole-mount immunohistochemistry on wild-type and homozygote embryos using $2 \mathrm{H} 3$ anti-neurofilament antibody showing the progression of cranial ganglion formation. (A,C) Wild-type and (B,D) mutant embryos at E9.5 and E10.5, respectively. Dorsal to the left, ventral to the right. $\mathrm{N}$ ote the ganglion IX in two different stages of embryos. Arrows in A and $C$ point to the nerve projections between the ninth ganglion and the hindbrain. Arrows in $B$ and $D$ point to the absence of nerve projection between the ninth ganglion and the hindbrain. The arrowheads in $B$ and $D$ point to the connections between ganglia IX and X. (V) Trigeminal ganglion; (VII) facial ganglion; (IX) glossopharyngeal ganglion; (X) vagus ganglion; (XI) accessory ganglion; (XII) hypoglossal nerve. ot, otic vesicle. Bar, $100 \mu \mathrm{m}$. which will be discussed later). No wild-type embryo examined appeared aberrant (Fig. 2A,C and Fig. 8A). The observed defects in the gl ossopharyngeal nerve could re sult from several reasons. To study how the loss of mCOUP-TFI resulted in the defects, we should first examine the expression of MCOUP-TFI in this and earlier developmental stages.

mCOU P-TFI is expressed in premigratory and migratory neural crest cells

The expression of mCOUP-TFI was evident at the one to two-somite stage (not shown), and increased at the four- to six-somite stage in the neuroepithelial region corresponding to the presumptive rhombomeres ( $r$ ) 1-3 in the hindbrain (Fig. 3A). At this stage, mCOUP-TFI expression was observed in a stripe extending ventrally from the dorsal tip of the middle of the neuroepithelial expression domain. The posterior boundary of the neuroepithelium expression corresponded to the posterior boundary of presumptive $\mathrm{r} 3$, as indicated by Krox-20 expression at the same stage (data not shown; Wilkinson et al. 1989), suggesting the stripe originated from the presumptive r2. mCOUP-TFI transcripts could also be seen in the developing foregut. At the 10- to 12-somite stage, mCOUP-TFI was expressed at high levels in the neuroepithelium and the dorsal edges of the presumptive r1-r4 and at low levels in the dorsal edges of the presumptive r5-r6. mCOUP-TFI transcripts were now detected in two stripes extending ventrally from the presumptive $r 2$ and r4 (Fig. 3B). The pattern and timing of the two stripes of mCOUP-TFI expression from $\mathrm{r} 2$ and $\mathrm{r} 4$ resemble that of the migrating neural crest cells (NCC) (Lumsden et al. 1991). The N C C migrate through well-defined pathways and occupy very characteristic positions (N oden 1988; Erickson and Perris 1993; Trainor and Tam 1995). Sections of embryos stained by whole-mount in situ hybridization showed that some mCOUP-TFI-expressing cells did occupy very characteristic positions of both premigratory and migratory N CC (Fig. 3D-F). This conclusion was further substantiated by the similar expression patterns of mCOUP-TFI and several other known NCC markers, including AP-2 (data not shown, Chazaud et al . 1996) and cellular retinoic acid-binding protein I (CRABP I, Fig. 5A, below, and Maden et al. 1992) at these stages. At E9.0, mCOUP-TFI was highly expressed in the entire hindbrian neuroepithelium and in the migrating NCC from $r 2, r 4$, and $r 6$ to branchial arches 1,2 , and 3 , respectively (Fig. 3C). The expression in the midbrain, forebrain, and other regions was similar to the pattern in later stages as reported previously (Qiu et al. 1994a; Pereira et al. 1995).

Segmentation and identity of the hindbrain and NCC migration is largely unchanged in mCOU P-TFI mutants

In light of the diverse expression pattern of MCOUP-TFI in the neuroepithelium, premigratory and migratory NCC, the observed defects in the gl ossopharyngeal nerve 


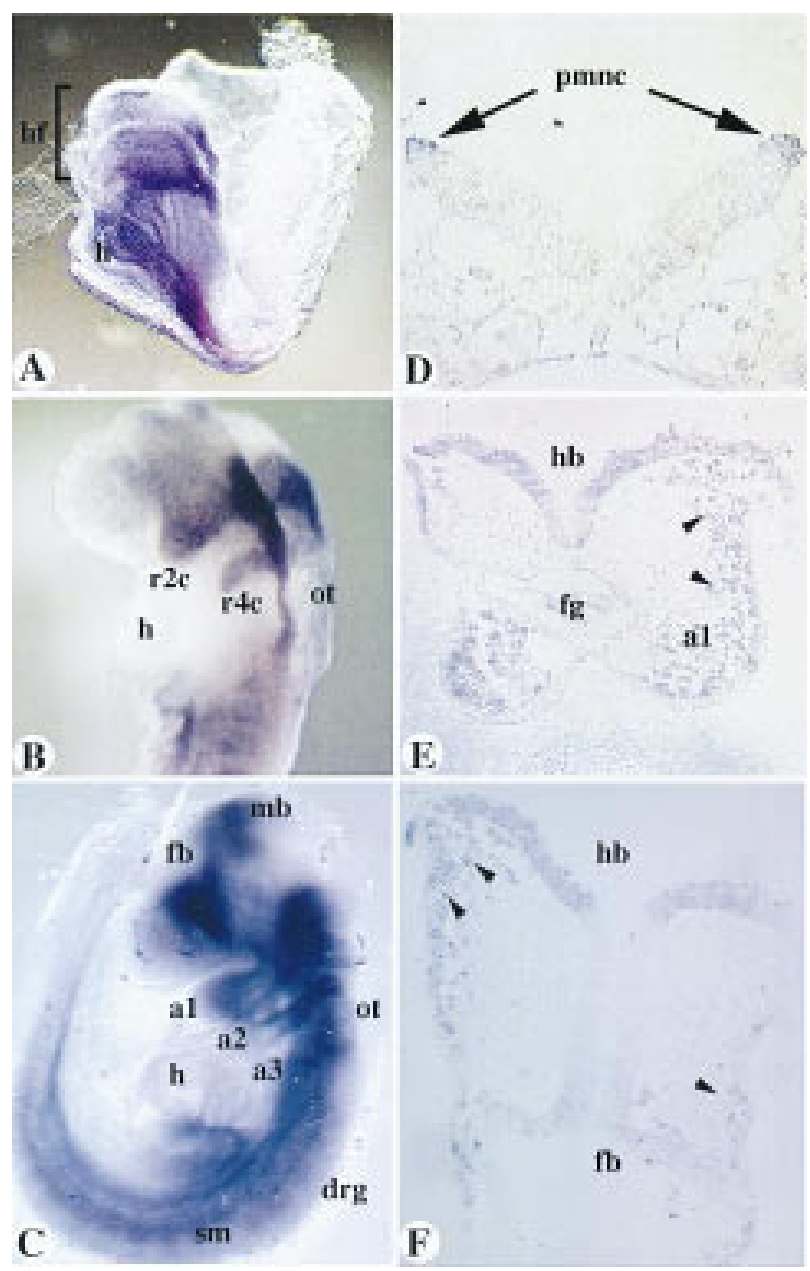

Figure 3. Expression of mCOUP-TFI. (A-C) Whole-mount in situ hybridization of mCOUP-TFI in E8.0 (A), E8.5 (B), and 9.0 (C) embryos, respectively. (D-F) Sections of a whole-mount stained E8.5 embryo. (a1, a2, a3) branchial arch 1, 2, and 3, respectively; (drg) dorsal root ganglia; (fb) forebrain; (h) heart; (hb) hindbrain; (hf) head fold; (fg) foregut; (mb) midbrain; (ot) otic vesicle; (pmnc) premigratory neural crest cells; ( $r 2 c, r 4 c)$ neural crest cells from $r 2, r 4$, respectively; (sm) somite. Arrows in D point to premigratory neural crest cells (NCC). A rrowheads in E and $\mathrm{F}$ indicate migrating NCC that are MCOUP-TFI positive.

may be a result of loss of mCOUP-TFI function in any or all of these regions. Thus, we examined the possibilities in detail. It is very intriguing that mCOUP-TFI is expressed in NCC as part of the ninth ganglion is derived from these special ized cells. The gl ossopharyngeal ganglion has two components; the inferior (petrosal) ganglion is derived from the second epibranchial placode, and the superior ganglion is derived from NCC that originate from r6 (D'Amico-M artel and Noden 1983; Lumsden et al. 1991). The fact that mCOUP-TFI is expressed in the NCC raises the possibility that the superior component of ganglion IX is defective in mutant embryos. However, in the mouse, unlike the chick, the superior and inferior components of ganglion IX are ana- tomically indistinct at these stages. In addition, because there is no known molecular markers that could distinguish the superior component from the inferior one in the ganglion, we have done our analyses at earlier embryonic stages before the NCC reach their final destination. NCC are prepatterned in the hindbrain and carry the identity of the rhombomere from which they emigrate ( $N$ oden 1983, 1988). The identities of the rhombomeres are established at molecular levels through a combinatorial expression of a number of genes at segmentally restricted patterns during hindbrain development (Lumden 1990; Wilkinson and Krumlauf 1990; Wilkinson 1993). To examine whether the segmentation and identities of the rhombomeres were retained in the mCOUP-TFI mutant embryos, several genes that are expressed in a segmental ly restricted fashion in the developing hindbrain were used as markers for the respective rhombomeres. The expression of Krox-20 in mCOUPTFI mutant embryos (Fig. 4C) followed the same profile as in wild-type embryos (Fig. 4A), where Krox-20 expression was first detectable in the future $r 3$ around E8.0 and the second stripe appeared in the future $r 5$ around E8.5. Subsequently, the expression in r3 decreased at E9.5 as previously defined (Wilkinson et al. 1989). Hoxb-1 is expressed at high levels in the neural tube at E8.0, extending from the posterior end of the embryo into the hindbrain with a sharp anterior boundary corresponding to the presumptive r3-r4 boundary. By E8.5, the expression domain in the neural tube retracts posteriorly except for the expression in $\mathrm{r} 4$, which persists until later stages (Murphy and Hill 1991). This dynamic expression of Hoxb-1 is unchanged in the mCOUP-TFI mutant as compared with the wild-type embryos (Fig. 4B,E). In the developing hindbrain neuroepithelium of E8.5-E9.5 embryos, CRABP I is highly expressed in $r 4, r 5$, and $r 6$ and much lower in r2 (M aden et al. 1992; Ruberte et al. 1992). Similar expression patterns were observed in both wildtype and mutant embryos (Fig. 4C,F). These results all ow us to conclude that all the rhombomeres have segmented appropriately and that their identities, as determined by rhombomere-specific molecular markers, are largely unchanged in the mCOUP-TFI mutant embryos.

Next, the migration of the NCC was examined. CRABP I is also an established marker for the migrating NCC (M aden et al. 1992). In E9.0-E9.5 embryos, it is intensely expressed in the migrating NCC from r4, r6, and weaker in those from $\mathrm{r} 2$ (Fig. 5A,B; Maden et al. 1992). The expression pattern of CRABP I in mCOUPTFI mutant embryos is similar to that in wild-type embryos (Fig. 5D,E). This result suggests that the migration of the cranial NCC is appropriate in mCOUP-TFI mutant embryos. To examine the NCC for ganglion IX, in situ hybridization was performed on coronal sections of E9.5 embryos using CRABP I antisense RN A as a probe. In both wild-type and mutant embryos, the neural crest cell population for ganglia IX and X were appropriately observed caudal to the otic vesicle (Fig. 5C,F). This study suggests that the NCC that would form the superior component of the glossopharyngeal ganglion migrated properly. 
Figure 4. Expression of rhombomere-specific genes in mCOUP-TFI mutants. Whole-mount in situ hybridization was performed on wild-type (A-C) or mutant embryos (D-F) with rhombomere specific markers. N ote expression is unchanged for mutants. (A,D) Krox-20 expression in $r 3$ and $r 5$ of E8.5 embryos. (B,E) Hoxb-1 expression in r4 of E9.0 embryos. (C,F) CRABP I expression strong in r4-r6, weak in $\mathrm{r} 2$ of E9.5 embryos.
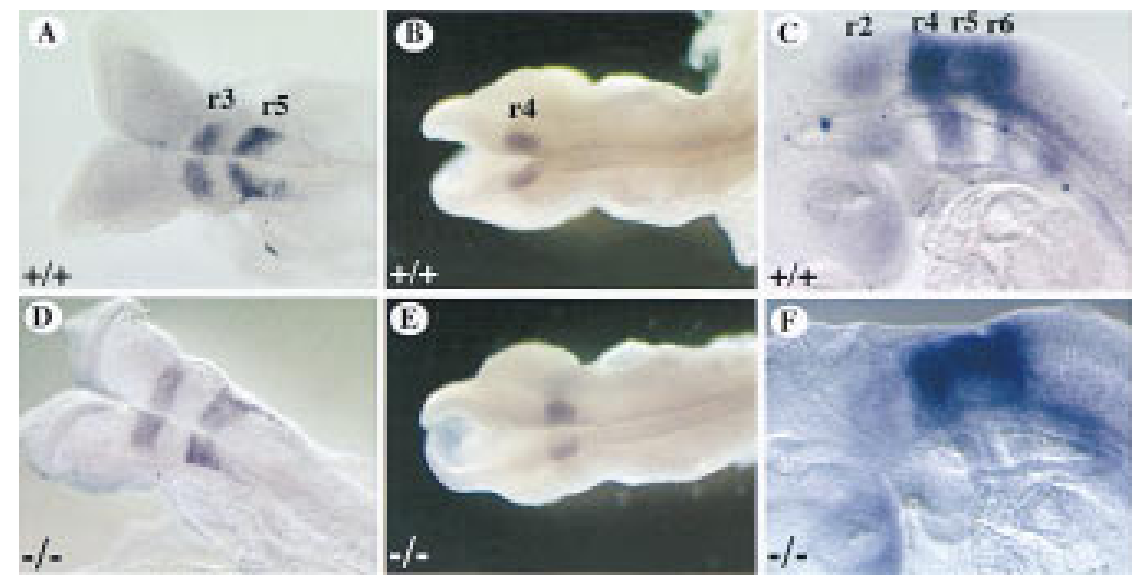

mCOUP-TFI mutants have a reduced number of neurons in the ninth ganglion

Although the NCC migrate appropriately, it is important to know whether the correct number of neurons exist at the ninth ganglionic position. Indeed, we noticed that the gangl ionic mass at gangli on IX was reduced fractionally in the more dorsal aspect of the ganglion. To visualize the ganglionic cells more easily, mCOUP-TFI mutants were crossed into the BETA2-LacZ background. BET A2/ N euroD is a basic hel ix-loop-helix transcription factor (Lee et al. 1995; N aya et al. 1995). A lacZ gene with a nuclear localization signal was placed in-frame with the BETA2 open reading frame when the BETA2 knockout mice were generated (F.J. N aya, H.-P. Huang, Y. Qui, H. Mutoh, F.J. DeM ayo, A.B. Leiter, and M.-J. Tsai, in prep.). BETA 2 is expressed early in developing cranial ganglia as visual ized by $X$-gal staining (F.J. N aya, H.-P. Huang, Y. Qui, H. M utoh, F.J. DeM ayo, A.B. Leiter, and M.-J. T sai, in prep.). Thefirst few differentiating neurons stained blue were observed at somite stage 17 in the trigeminal ganglion and subsequently the blue neurons were observed in all the differentiating cranial ganglia (F.J. N aya, H.-P. Huang, Y. Qiu, H. Mutoh, F.J. DeM ayo,
A.B. Leiter, and M.-J. Tsai, in prep.). Mice heterozygous for the BETA2 gene have no detectable defects. Therefore, the BETA 2 gene expressi on was used as a marker for ganglionic cell bodies in our study. The defect in the mutant ninth ganglion was fully manifested at E10.5 (Fig. 6C,D), the number of neurons in both wild-type and mutant ninth gangl ia were counted. Indeed, the number of neurons in ganglia IX was significantly lower ( $40 \%)$ in the mutants than in the wild types or heterozygotes (Table 2). As a control, neurons in ganglia $X$ of the same embryos were counted and the numbers were not si gnificantly different between the mutant and the wild-type or heterozygous embryos. This suggests that some precursor cells of ganglion IX must have died prematurely, changed fate, or migrated to a different position.

mCOU P-TFI mutant embryos display pronounced cell death in a region dorsal to the ninth ganglion

Some cell death occurs during normal embryonic development at early stages and patterns of the cell death correspond to routes of neural crest migration (Jeffs et al. 1992; Jeffs and Osmond 1992). It is thought that many
Figure 5. Analysis of cranial NCC migration in mCOUP-TFI mutants. Wild-type (A-C) or mutant embryos (D-F) were hybridized with CRABP I antisense probe to examine the migration of the neural crest cells. Whole-mount in situ hybridization on E9.0 (A,D) and E9.5 (B,E) embryos. (C,F) in situ hybridization with CRABP I antisense probe on sections of late E9.5 embryos. (c9-c10) N eural crest cells for ganglia IX and $X$; (fn) frontal nasal mesenchyme; (r) rhombomere; ( $r 2 c, r 4 c, r 6 c)$ neural crest cells from $r 2, r 4, r 6$, respectively; (ot) otic vesicle; $(4,5$, and 6$) \mathrm{r} 4, \mathrm{r} 5$, and $\mathrm{r} 6$, respectively.
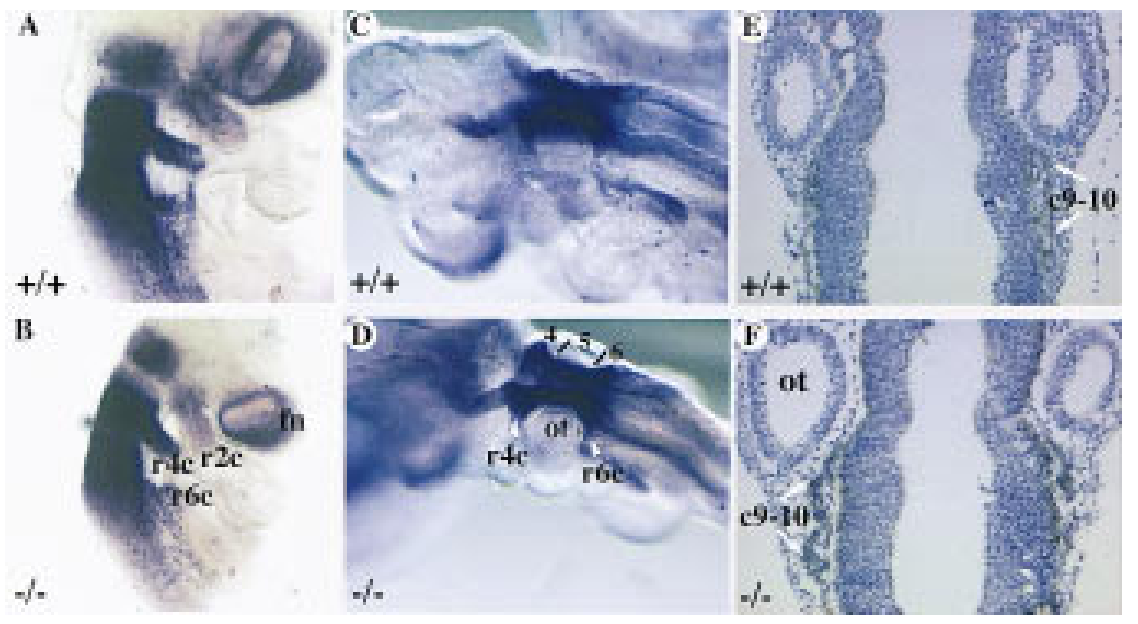


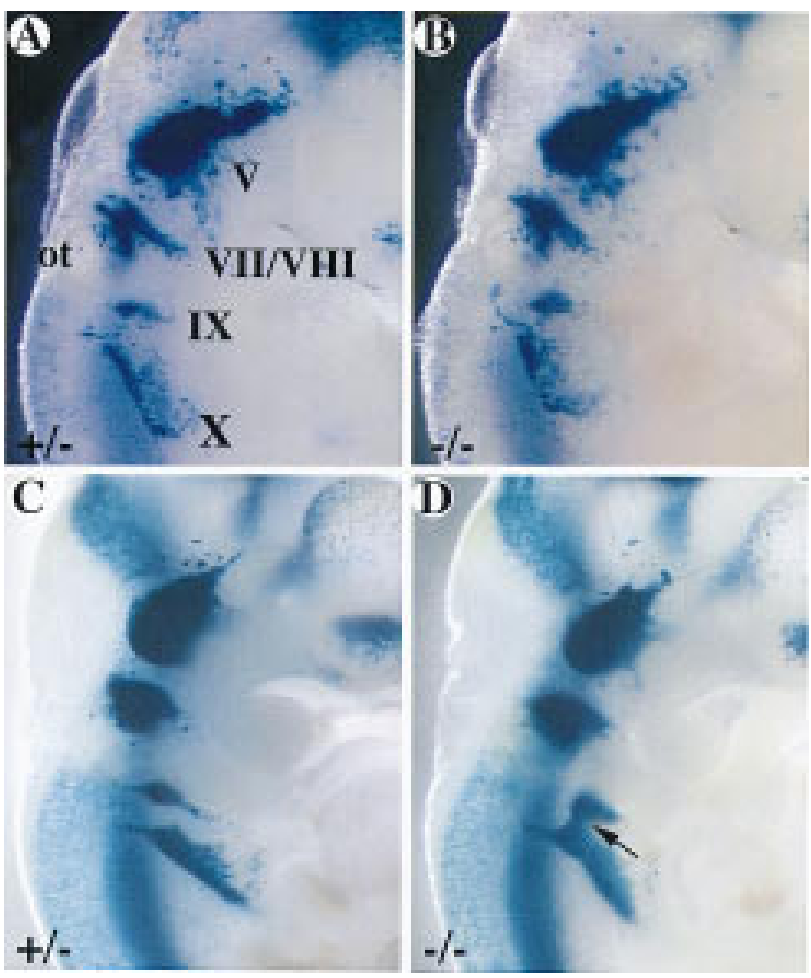

Figure 6. Developmental progression of the formation of ganglion IX as visualized by $X$-gal staining. mCOUP-TFI wild-type $(A, C)$ and mutant $(B, D)$ embryos at E9.5 (A,B) and E10.5 (C,D) were stained with $X$-gal. $A$ and $B$ were among the embryos used for apoptosis study; $C$ and D were among the embryos used for neuronal counting, as shown in Table 2. (V) Trigeminal ganglion; (VII/VIII) facial and acoustic ganglia; (IX) glossopharyngeal ganglion; $(X)$ vagus ganglion. Arrow indicates the fusion between ganglia IX and $X$ in the mutant embryo.

more NCC are born than are required during development. To visualize the apoptotic cells, TUNEL assay was performed on sections of $X$-gal-stai ned late E9.5 embryos (Fig. 6A,B). Consistent with previous reports (leffs et al. 1992), limited cell death was observed in regions of developing cranial nerve migration routes including those of the ninth nerve in wild-type or heterozygous embryos (Fig. 7A-D). In contrast, similarly staged mutant embryos showed much more pronounced cell death in the corresponding region just dorsal to the ninth ganglion (Fig. 7E-H). The region of cell death corresponded to the

Table 2. Counts of neurons in the IXth and Xth ganglia of COUP-TFI embryos

\begin{tabular}{lcc}
\hline Ganglion & $H+, H-$ & $--^{\mathrm{a}}$ \\
\hline $\mathrm{IX}$ & $99.0 \pm 3.5$ & $60.4 \pm 1.0$ \\
& $(\mathrm{n}=8)$ & $(\mathrm{n}=5)$ \\
$\mathrm{X}$ & $170.3 \pm 4.5$ & $178.2 \pm 9.0$ \\
& $(\mathrm{n}=7)$ & $(\mathrm{n}=5)$ \\
\hline
\end{tabular}

Values represents mean \pm S.E.M.

a- - -differs from $H+$ or $H-$; $<0.001$. expression domain of CRABP I and to the known migratory route of N CC for ganglion IX (cf. Fig. 5C,F), suggesting that at least some of the apoptotic cells in the mutant embryos might be of neural crest origin. In most cases, the excess cell death was only seen on one side of the mutant embryos. This correl ates well with the observation that the defective ganglion IX was commonly seen on one side of a given mutant embryo by neurofilament staining. Collectively, these data suggest that the excess cell death during the migratory phase of the NCC result in a decrease in differentiating neurons in the mutant ganglion IX. This suggests that the superior component

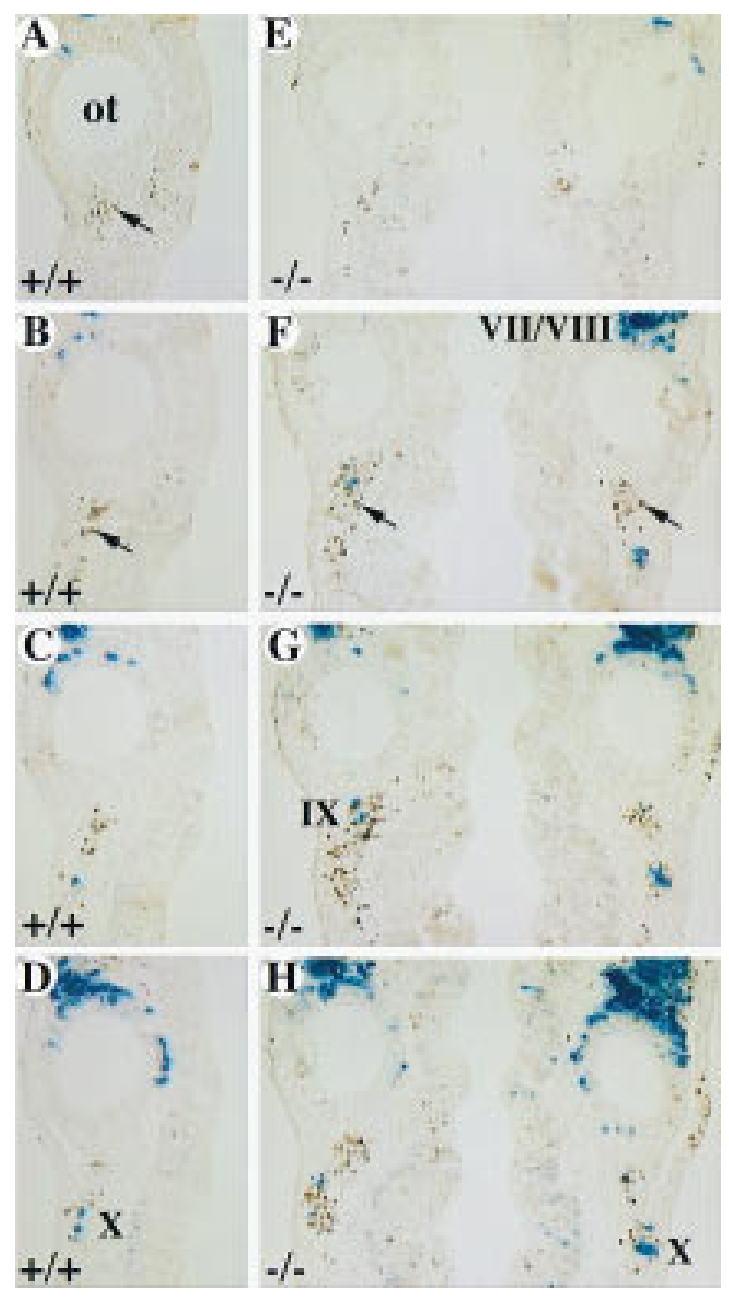

Figure 7. Excessive cell death in mCOUP-TFI mutant embryos. mCOUP-TFI mutant (A-D) and wild-type (E-H) embryos at E9.5 were stained with X-gal, sectioned, and TUNEL assay was performed. Every other section in the region of interest is presented. Sections at top are more dorsal than the sections at the bottom. N ote that the left side of the mutant embryo shows much more pronounced cell death than in the wild type. (ot) Otic vesicle; (VII/VIII) facial and acoustic ganglia; (X) vagus ganglion. Note that IX marks a position dorsal to ganglion IX proper, which lies further ventral. (Arrows) A poptotic cells. 
of the glossopharyngeal ganglion is most likely compromised.

mCOUP-TFI mutants exhibit defects in axonal guidance

Besides being defective in the formation of the superior ganglion, ganglion IX in mutants formed no correct connections with the hindbrain (Fig. 8D,F). Instead, axons fasciculated with cranial nerve $X$ in some cases. Thus, this is consistent with an axonal guidance defect. In fact, this is a more general problem in mCOUP-TFI mutants. In addition to the defect in the glossopharyngeal nerve, abnormalities in other nerve projections were also observed in some embryos at E10.5. As shown in Figure 8, severely affected mutants display aberrant nerve fibers running down the caudal part of the hindbrain on both sides of the embryo (see asterisk in Fig. 8E,F). The origin of the nerve fibers was not clear. In addition, the oculomotor nerve (III) at the left side of the embryo (Fig. 8H) appeared as a shortened and broadened bundle when compared to the right side or wild-type embryos (Fig. $8 \mathrm{G}, \mathrm{I})$.

In addition to the aberrant projections, mutant embryos al so displayed aberrant arborization at later developmental stages. When older embryos (E11.5-E13.5) were stained with the $2 \mathrm{H} 3$ antibody, it was clear that the extent of arborization or branching of the axonal trees was affected in about half of the mutant embryos at the facial and cervical plexus regions. The cervical plexus is formed by the first four spinal nerves (Kahle 1993a). In E11.5 wild-type embryos, the nerve fi bers were aborized extensively (Fig. 9A), whereas in the mutants, the primary axons appeared thicker and there were less secondary branchings and much less tertiary or higher order branchings (Fig. 9B). A similar defect was also observed in the ophthalmic branch of the trigeminal nerve (Fig. $9 C, D)$, where there were fewer secondary as well as high order branchings. The arborization in other regions of the mutant embryos appeared relatively normal. These results clearly suggest that MCOUP-TFI is required for normal axonal guidance and arborization in a subset of neurons in the peripheral nervous system.

\section{Discussion}

We have shown that deletion of the mCOUP-TFI gene from the mouse genome results in perinatal lethality. The null mutants displayed defects in morphogenesis of the glossopharyngeal ganglion and its nerve and in axonal arborization in various areas. The results suggest that mCOUP-TFI is required for proper fetal development and is essential for postnatal survival.

The morphogenesis of the glossopharyngeal ganglion and its nerve is defective in mCOUP-TFI mutant embryos as shown by neurofilament staining. The glossopharyngeal nerve is the nerve of the third pharyngeal arch. It supplies both sensory and motor innervation to the pharynx and root of the tongue. It also innervates the middle ear and soft palate. Together with the vagus nerve (cranial nerve $\mathrm{X}$ ), nerve IX registers and regulates blood pressure and pulse rate (Gilman and N ewman 1989; Kahle et al. 1993b). The cell bodies of the sensory and taste fibers reside in ganglion IX and the fibers terminate in the nucleus solitarius in the hindbrain. The motor fibers originate from the cranial part of nucleus ambiguus and the secretory fibers stem from the inferior salivary nucleus in the hindbrain. These fibers pass through the gangl ion and terminate on the target organs (Lumsden and Keynes 1989; Kahle et al. 1993b). Thus, proper connection between the ganglion and the appropriate nuclei in the brainstem is crucial for the proper function of the ninth nerve. In the mCOUP-TFI mutant embryos, ganglion IX either appeared as an isolated ganglionic mass or fused with gangl ion $X$. Indeed, there were

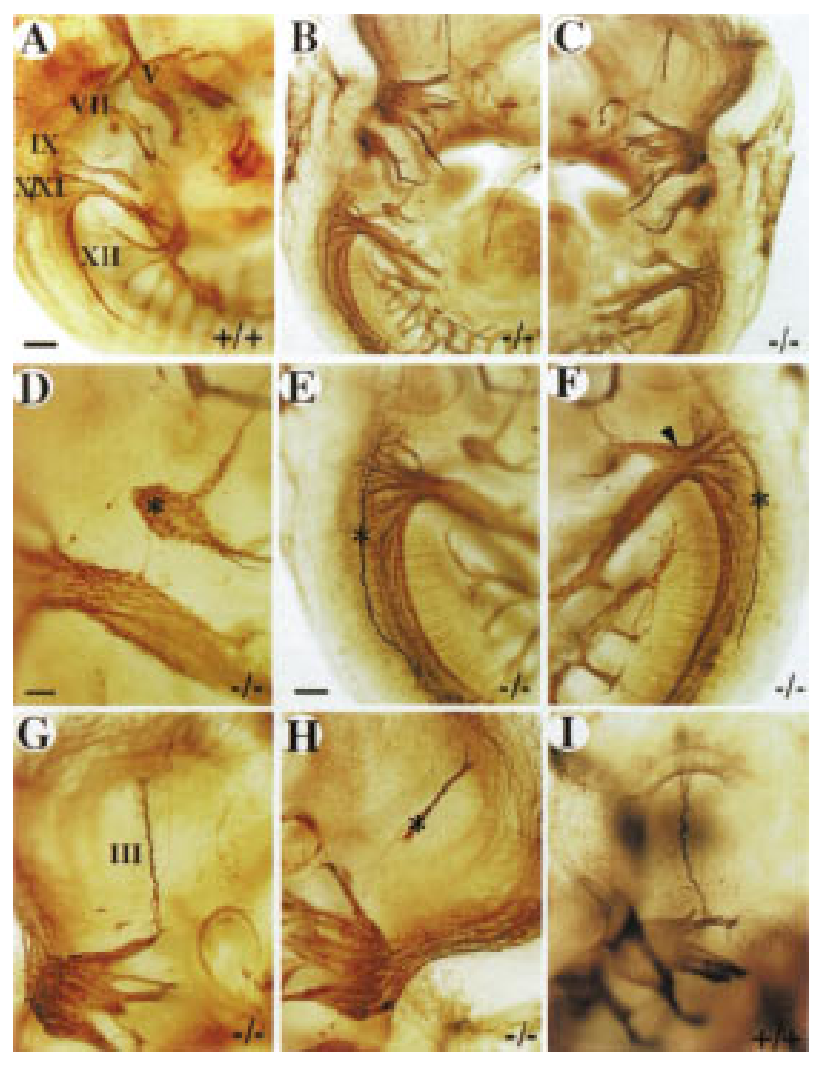

Figure 8. Whole-mount analysis of axonal projections. Multiple defects in cranial nerve projections are detected in severely affected embryos. (A) wild-type E10.5 embryo. The right (B) and the left (C) side of a E10.5 mutant embryo. (D-F) Enlargement of cranial nerve IX-XII region from $B$ and $C$. N ote the isolated ganglionic mass (asterisk in $D$ ) at the position of the ninth ganglion, the abnormal projection of a single nerve fiber toward the hindbrain (D) and the abnormal axonal bundles (asterisk in E,F) on both sides of the hindbrain. N ote the extensive fusion of nerve IX and $X$ on the left side of the animal (arrowhead in F). $(\mathrm{G}, \mathrm{H})$ Enlargement of the oculomotor nerve (III) region in B and C. Note the abnormal projection of nerve III on the left side (asterisk in H). (III) Oculomotor nerve; (V) trigeminal ganglion; (VII) facial ganglion; (IX) glossopharyngeal ganglion; (X) vagus ganglion; (XI) accessory ganglion; (XII) hypoglossal nerve. (A-C) Bar, $100 \mu \mathrm{m}$; (E-H) bar, $50 \mu \mathrm{m}$; (D) bar, $20 \mu \mathrm{m}$. 


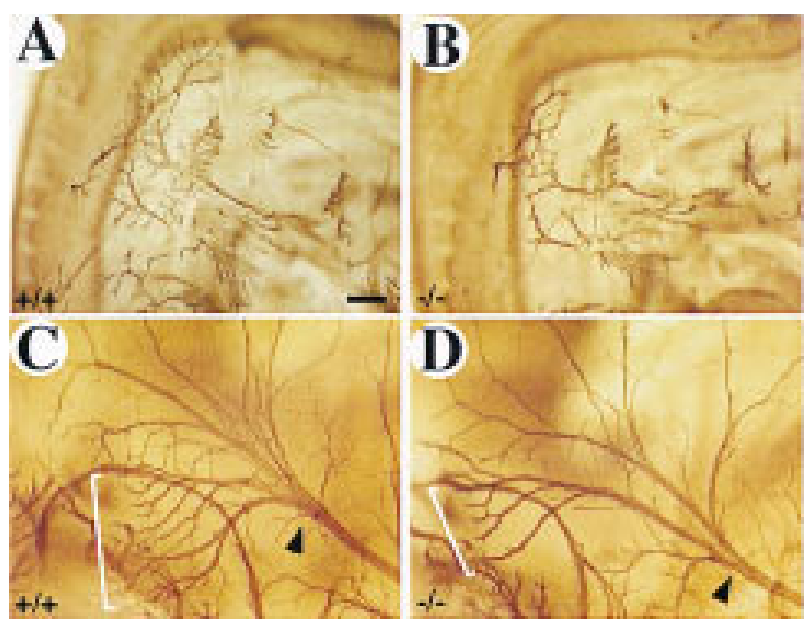

Figure 9. mCOUP-TFI mutant embryos display reduced arborization of axonal trees. Whole-mount immunohistochemistry of wild-type $(A, C)$ and mutant E11.5 fetuses $(B, D)$ using $2 \mathrm{H} 3$ anti-neurofilament antibody. $(A, B)$ Sagittal views at the level of posterior hindbrain and anterior somite region showing arborization of the first several spinal nerves. $\mathrm{N}$ ote the reduced arborization in the mutant fetuses. (C,D) Higher magnification of the ophthalmic branch of the trigeminal nerve. Arrowheads point to the corresponding branching points in the wild-type and mutant embryos. Note the extensive branchings in the wild type. Also, note the less extent of arborization in the bracketed region.

no connections to the hindbrain through its normal route. Therefore, it is most likely that the function of the glossopharyngeal nerve is severely compromised. Because the mutants die from apparent starvation and dehydration, they might have difficulty in obtaining exogenous nutrients that are critical for their survival. Among the targets of the glossopharyngeal nerve, the innervation to the pharynx and the root of the tongue might be most important regarding the lethal phenotype of mCOUP-TFI mutants, as proper control of the tongue and the pharynx is required for proper suckling and swallowing behavior. In fact, when tested by putting a drop of milk around their mouth, wild types or heterozygotes could easily drink and swallow 30-50 $\mu$ l of milk. In contrast, the mutants displayed abnormal throat movements after taking in the milk and soon the milk was expelled from the nasal cavity, suggesting that the mutant pups did exhibit difficulty in swallowing. However, as in most cases, the defect in ganglion IX was only observed at one side, most likely this was not the sole contributor to the lethality of the MCOUP-TFI mutant pups. Indeed, as ganglion IX was often fused with ganglion $X$ in the mutant embryos, we cannot exclude the possibility that the function of nerve $X$ is compromised.

mCOUP-TFI is required for proper formation of the glossopharyngeal nerve

The ganglion of the gl ossopharyngeal nerve contains two components: the superior and the inferior (petrosal) gan- glion. In the superior ganglion, both the neurons and the nonneuronal cells are derived from the neural crest cells of $r 6$. In the inferior ganglion, the neurons origi nate from the second epi branchial placode, whereas all the nonneuronal cells are derived from neural crest cells of r6 (D'A mico-M artel and N oden 1983; Lumsden et al. 1991). Because mCOUP-TFI is expressed in premigratory and migratory neural crest cells, it is possible that the neural crest-derived component of ganglion IX is defective. In fact, the altered morphol ogy of gangl ion IX in the mutant embryos supports this hypothesis. However, there is no easy way to test this hypothesis as there is no well-characterized molecular marker that only expresses in the superior ganglion. The defect would range from improper NCC fate specification, migration, to differentiation. Analysis using various rhombomere-specific and migrating neural crest markers did not reveal any consistent difference between mutant and control embryos in terms of the expression pattern and profile, especially in the r6 region and its associated NCC. This suggested that the NCC from r6 were appropriately fated and migrated toward arch 3 in mCOUP-TFI mutant embryos. This conclusion was consistent with the observation that the muscular and skeletal derivatives of the third pharyngeal arch were apparently normal in mCOUP-TFI mutant pups. The majority of the NCC from $\mathrm{r} 6$ migrate into pharyngeal arch 3 , which later differentiates into the greater horn and lower portion of the body of the hyoid bone and the stylopharyngeus muscle (Noden 1988). M ore important, the NCC marker gene expression implied that the NCC destined for the superior component of ganglion IX were fated and migrated properly. However, the number of neurons in ganglia IX of the mutant embryos was reduced by $40 \%$ when compared to that in the wild-type embryos at E10.5. This suggests that either the NCC for ganglia IX in mutants are defective in proper differentiation or that the neuron loss in the mutant ganglia is not of neural crest origin.

To clarify the possibilities, we analyzed the extent of cell death in these regions. There is a limited amount of cell death in specific regions during normal embryonic development. The best known example is the cell death in the interdi gital necrotic zones of the vertebrate limb. These cells undergo programmed cell death on a schedule even when explanted into culture (Fallon and Saunders 1968). Most of the apoptotic cells in other regions are neural crest in origin (Lumsden et al. 1991; Jeffs et al. 1992; Jeffs and Osmond 1992). However, the life or death decision of the NCC is influenced by environment and position. For example, the N CC generated in $\mathrm{r} 3$ and $\mathrm{r} 5$ do not emigrate, instead, they undergo apoptosis. Yet, when r3 or r5 is explanted into culture, the NCC migrate out perfectly because now they are free from the influence of the even number rhombomeres (Graham et al. 1993). Cell death has been detected along the migratory routes of NCC, including regions of the devel oping ganglia VII / VIII and ganglion IX. At late E9.5 embryos, a few apoptotic cells were observed in a region just dorsal to the developing ninth ganglion in wild-type or heterozygous embryos. In contrast, much more pronounced cell death 
was observed in a similar region of the mutant embryos. The apoptotic cells occupi ed the same region as the neural crest cells for ganglion IX. Thus, more than likely, at least some of the apoptotic cells are neural crest in origin, which in turn suggests that the neuron loss is in the superior component of ganglion IX. Collectively, this evidence suggests that the excessi ve precursor cell death results in a decrease of neurons in the glossopharyngeal ganglia of mCOUP-TFI mutant embryos and most likely the defect is in the superior component.

Because NCC contribute to all the nonneuronal cells in both superior and inferior ganglion and as nonneuronal cells are present in the ninth ganglia of the mutant embryos, it is clear that not all the neural crest cells for ganglion IX undergo apoptosis. It is not known whether the neurons undergo apoptosis sel ectively. Y et, it is possible that there are also less nonneuronal cells in the mutant ninth ganglion than in the wild type. In addition, it seemed that the apoptotic domain in the mutant embryos extended toward ganglion $\mathrm{X}$. Although the number of neurons in the tenth ganglia of the mutant embryos did not differ significantly from the wild-type or heterozygous embryos, we could not exclude the possibility that the formation of ganglion $X$ is slightly compromised.

Reasons for NCC death during normal embryonic development is unclear. It could be either a response to an overproduction of the N CC or it could contribute to patterning the neural crest migration pathway (Jeffs et al. 1992; Jeffs and Osmond 1992). The excess death observed around the mutant ganglion IX is a consequence of the Ioss of function of the mCOUP-TFI gene. Thus, it is possible that this group of cells did not receive or could not respond to appropriate signals for differentiation and switched to programmed cell death or apoptosis instead. However, it is not known whether the apoptosis is a consequence of lack of mCOUP-TFI function in NCC themselves or in the surrounding environment. Besides ganglion IX, ganglia V, VII/VIII, and X also have neural crest contribution. However, obvious defects were only observed on ganglion IX. One possibility is that the formation of the other ganglia does not require mCOUPTFI function. Alternatively, the lack of mCOUP-TFI function in those regions is compensated by other genes such as mCOUP-TFII, which is expressed similarly as mCOUP-TFI although in a less restricted manner.

mMCOU P-TFI activity is necessary for proper axonal guidance

In developing embryos, nerve fi bers have to navigate for long distances before reaching their targets. The pathfinding process has high fidelity because of the guidance molecules presented in the surrounding environment that are sensed by the growth cones (Tessier-Lavigne and Goodman 1996). There are several kinds of guidance cues, including long range (diffusible molecules) and short range (contact mediated), both could be positive or negative. $\mathrm{N}$ ormally, multiple guidance cues in the sur- rounding environment are presented to a given growth cone. The net outcome is determined by the bal ance be tween different forces (Tessier-Lavigne and Goodman 1996). The nerve fibers in the cervical plexus and facial regions of many mCOUP-TFI null mutants were much less arborized than their wild-type or heterozygous littermates and can be assigned to defects in axonal guidance. Axonal branches could be formed either by collateral initiation of secondary growth cones al ong the axon shaft or by bifurcation of the primary growth cones. This process involves initiation, stabilization, and outgrowth of the secondary growth cones. Many transient branches are formed, but only few are stabilized (Sato et al. 1994). The higher order branches are formed in a similar way (Sato et al. 1994). Both the initiation and subsequent guidance of the secondary growth cones are believed to be governed by the same forces that guide the primary growth cones (Roskies and O'Leary 1994).

This abnormal axonal guidance in MCOUP-TFI mutant embryos could be the result of a loss of MCOUP-TFI in the neurons themsel ves. In the case of gangl ion IX, the connection to the hindbrain was altered or absent in the mutants. It is possible that loss of neurons in the superior component affects the proper development of the remaining ganglionic cells. Conversely, the apoptotic cells in the mutants included some cells that would themselves present guidance cues for the proper axonal projection to the hindbrain. In addition, the aberrant arborization in the cervical pl exus could al so be a defect in the dorsal root ganglionic neurons as they are also derivatives of the NCC. The other obvious possibility is that the expression of gui dance molecules is al tered from lack of mCOUP-TFI function. Most of the affected nerves do not grow or arborize sufficiently, yet severely affected mutants have aberrant fibers running down the hindbrain, which implies an overgrowth of the axons. It is uncl ear whether the defects in axonal guidance in the various regions are directly caused by changes in a single guidance molecule or by multiple molecules. Even if the expression of a single guidance molecule is altered in mCOUP-TFI mutants, different phenotypes could be manifest because it is the collective information from attractive and repulsive guidance cues in the environment that determine the action of a growth cone. Furthermore, one guidance cue could be positive for some axons yet negative for others (Tessier-Lavigne and Goodman 1996).

In conclusion, we have shown that mCOUP-TFI is essential for postnatal survival and required for proper development of a subset of neurons in the peripheral nervous system. M utant embryos displ ayed a defective morphogenesis of the glossopharyngeal ganglion and nerve. Inactivation of mCOUP-TFI gene al so resulted in defective axonal guidance. Interestingly, mCOUP-TFI is widely expressed, yet the phenotypes exhibited by the mutants were very specific. This suggests that in the other regions, the function of mCOUP-TFI might be compensated by mCOUP-TFII. Nevertheless, the fact that mCOUP-TFI knockout is lethal provides convincing evidence that mCOUP-TFI indeed possesses distinct 
physiological functions despite its extensively overlapping expression profile with mCOUP-TFII.

\section{Material and methods}

\section{Targeting vector construction}

A mouse 129Sv genomic library (a gift from P. Soriano, Fred Hutchison Institute, Seattle, WA) was screened with a mouse cDNA fragment containing the complete mCOUP-TFI open reading frame. Several of the positive clones contained all three exons of mCOUP-TFI gene (Qiu et al. 1995). A 700-bp fragment containing the $5^{\prime}$ untranslated region was excised with EcoRISacl and used as the $5^{\prime}$ homologous arm in the gene-targeting vector. The Sacl site was destroyed during subsequent subclonings. A $6.5-\mathrm{kb}$ fragment containing part of exon 2 and the entire exon 3 was excised with Sall-Sacl and used as the right arm. The PGK-neobpA gene (neor) (Soriano et al. 1991) was digested with Sall-Xhol and inserted in the same transcriptional direction as the MCOUP-TFI. The left arm, PGK-neobpA, and the right arm were assembled in pBluescript, released with XholBamHI, and cloned into Xhol-BamHI of pSP72TK containing the herpes simplex virus thymidine kinase gene ( $M$ ansour et al. 1988). The construct was linearized with Xhol before electroporation.

\section{Electroporation and selection of ES cells}

The ES cells were cultured and manipulated essentially as described by Robertson (1987). Briefly, 107 AB1 ES cells (M cMahon and Bradley 1990) were el ectroporated with $25 \mu \mathrm{g}$ targeting construct in $0.9 \mathrm{ml}$ of PBS using a Bio-Rad Gene Pulser (500 $\mu \mathrm{F}$, $230 \mathrm{~V}$ ), and plated on either one or two $10-\mathrm{cm}$ plates containing a monolayer of mitomycine C-treated fibroblast SN L76/7 (M cMahon and Bradley 1990). Twenty-four hours later, the media was replaced with selection media containing $350 \mu \mathrm{g} / \mathrm{ml}$ of G418 (GIBCO) and $0.2 \mathrm{~mm}$ FIAU, and cells were cultured for an additional 9 days. Individual drug-resistant colonies were picked and expanded in 96-well plates containing feeder cells.

\section{Screening the G418-resistant colonies and genotyping mice}

For screening the ES cell colonies, the cells were trypsinized in situ and two-thirds were frozen at $-80^{\circ} \mathrm{C}$. The remaining cells were replicated into a new 96-well plate without feeder cells and grown to confluency for DNA isolation. The DNA was isolated and digested within the 96-well plates as described previously (Romirez-Solis et al. 1992). Southern blot analysis was carried out according to Church and Gilbert (1984). For genotyping mice and older embryos (E10.0 and older), genomic DNAs were isolated from tail biopsies or the yolk sac, respectively, after overnight proteinase $\mathrm{K}$ treatment and ethanol precipitation. The DN A was then subjected to Southern analysis or PCR. For younger embryos, the yolk sac was treated with proteinase $\mathrm{K}$ overnight, heated to $90^{\circ} \mathrm{C}$ for $10 \mathrm{~min}$, and used for PCR directly. To detect the wild-type allele, the $5^{\prime}$ primer was 5'-CACGGACCAGGTGTCTCTG-3', located in a region of exon 2 that was del eted in the mutant allele. The $3^{\prime}$ primer was 5'-CTGACGTGAATAGCACGATG-3', located at the end of exon 2, 3' to the Sall site. To detect the mutant allele, the same 3' primer was used. The $5^{\prime}$ primer was 5'-GCTATCAGGACATAGCGTTG-3', located at the $3^{\prime}$ end of the PGK-neo gene. PCR was performed according to the manufacturer's instructions (Promega), with $1.0 \mathrm{~mm} \mathrm{M} \mathrm{gCl}_{2}$, at the annealing temperature of $55^{\circ} \mathrm{C}$.

\section{Generation of chimeric mice and animal breeding}

The positive clones identified from the screening were thawed, expanded, and injected into E3.5 blastocysts derived from C57BL/ 6 females. The embryos were transferred into the uteri of pseudopregnant $F_{1}(C B A \times C 57 B L / 6)$ foster mothers. Male chimeras with $80 \%-100 \%$ agouti coat color were backcrossed to $\mathrm{C} 57 \mathrm{BL} / 6$ females, and germ-line transmission was determined by the presence of agouti offspring. Heterozygotes were determined by Southern analysis and intercrossed to generate homozygotes.

\section{Whole-mount immunohistochemistry}

Whole-mount immunohistochemistry with a monoclonal antibody $(2 \mathrm{H} 3)$ recognizing a $165-\mathrm{kD}$ neurofilament protein was performed essentially as described (Wall et al. 1992). Briefly, embryos were collected in PBS, fixed in methanol:DMSO (4:1) overnight at $4^{\circ} \mathrm{C}$. The embryos were then bleached in methanol:DM SO:30\% $\mathrm{H}_{2} \mathrm{O}_{2}$ (4:1:1) for 4-5 hr at room temperature, rehydrated for $30 \mathrm{~min}$ each through $50 \%$ and $15 \%$ methanol, and finally PBS. Embryos were incubated twice in PBSMT (2\% instant skim milk powder, $0.1 \%$ Triton X-100 in PBS) for $1 \mathrm{hr}$ at room temperature, then with primary antibody diluted in PB$\mathrm{SMT}$ at $4^{\circ} \mathrm{C}$ overnight. Embryos were washed in PBSMT twice at $4^{\circ} \mathrm{C}$ and 3 times at room temperature for $1 \mathrm{hr}$ each, followed by an overnight incubation at $4^{\circ} \mathrm{C}$ with peroxidase-conjugated goat anti-mouse IgG diluted in PBSMT. The washes were similar to washes after the primary antibody one with an additional $20-$ min wash in PBT (0.2\% BSA, $0.1 \%$ Triton $\mathrm{X}-100$ in PBS) at room temperature. For the color reaction, embryos were incubated with $0.3 \mathrm{mg} / \mathrm{ml}$ of diaminobenzidine tetrahydrochloride (Sigma) in PBT for 30-60 min at room temperature, and visualized by addition of $\mathrm{H}_{2} \mathrm{O}_{2}$ to $0.0003 \%$ and incubation at room temperature. Embryos were then rinsed in PBT to stop the reaction, dehydrated through a methanol series; $30 \%, 50 \%, 80 \%$, $100 \%$ for 30-60 min each, and cleared in benzyl al cohol :benzyl benzoate (1:2). Embryos were photographed on a Zeiss stemi 200 dissecting microscope.

\section{Whole-mount in situ hybridization}

Whole-mount in situ hybridization was performed according to Wilkinson (1992). A mCOUP-TFI cDNA clone containing the entire open reading frame was used as the template for transcribing digoxigenin-labeled anti-sense probe. The same probe did not generate a hybridization signal in homozygote mCOUPTFI mutant embryos.

\section{$X$-gal staining}

$X$-gal staining of the embryos was performed as described by Behringer et al. (1993).

\section{TUNEL assay}

TUNEL assay was performed as described by Gavrieli et al. (1992).

\section{Neuron counting}

The embryos were stained with $\mathrm{X}$-gal, then processed and embedded in paraffin. N eurons were counted from every sixth section of 7- $\mu \mathrm{m}$ thick sections. In the cases when ganglia IX and X were fused, the cells rostral to ganglion $X$ were counted as cells 
for ganglion IX. Statistical significance was analyzed by Student's t-test.

\section{Acknowledgments}

We thank Drs. Richard Behringer, Hugo Bellen, Gregor Eichele for valuable discussions, and Meijun Chu, LouAnn Hadsell, Kelli Bramlett for excellent technical assistance. This work was supported by $\mathrm{N}$ ational Institutes of $\mathrm{Health}$ grants to M.J.T. and S.Y.T. Y.Q. is supported by a $\mathrm{N}$ ational Research Service A ward fell owship. F.A.P. is supported by a fell owship from the M edical Research Council of Canada.

The publication costs of this article were defrayed in part by payment of page charges. This article must therefore be hereby marked "advertisement" in accordance with 18 USC section 1734 solely to indicate this fact.

\section{References}

Behringer, R.R., D.A. Crotty, V.M. Tennyson, R.L. Brinster, R.D. Palmiter, and D.J. Wolgemuth. 1993. Sequences $5^{\prime}$ of the homeobox of the Hox-1.4 gene direct tissue-specific expression of LacZ during mouse development. Development 117: 823-833.

Chazaud, C.M., M. Oulad-A bdel ghani, P. Bouillet, D. Decimo, P. Chambon, and P. Dolle. 1996. AP-2.2, a novel gene related to AP-2, is expressed in the forebrain, limbs and face during mouse embryogenesis. Mech. Dev. 54: 83-94.

Church, G.M. and W. Gilbert. 1984. Genomic sequencing. Proc. Natl. Acad. Sci. 81: 1991-1995.

Cooney, A., S. Tsai, B.W. O'Malley, and M.-J. Tsai. 1992. Chicken oval bumin upstream promoter transcription factor (COUP-TF) dimers bind to different GGTCA response elements, allowing COUP-TF to repress hormonal induction of the vitamin D3, thyroid hormone, and retinoic acid receptors. Mol. Cell. Biol. 12: 4153-4163.

Cooney, A., X. Leng, S. Tsai, B.W. O'M alley, and M.-J. Tsai. 1993. Multiple mechanisms of chicken oval bumin upstream promoter transcription factor-dependent repression of transactivation by the vitamin $\mathrm{D}$, thyroid hormone, and retinoic acid receptors. J. Biol. Chem. 268: 4152-4160.

D'Amico-M artel, A. and D.M. Noden. 1983. Contributions of palcodal and neural crest cells to avian cranial peripheral ganglia. Am. J. A nat. 166: 445-468.

Dodd, J., S.B. Morton, D. Karagogeos, M. Yamamato, and T. Jessell. 1988. Spatial regulation of axonal glycoprotein expression on subsets of embryonic spinal neurons. Neuron 1: $105-116$

Erickson, C.A. and R. Perris. 1993. The role of cell-cell and cell-matrix interactions in the morphogenesis of the neural crest. Dev. Biol. 159: 60-74.

Fallon, J.F. and J.W. Saunders. 1968. In vitro analysis of the control of cell death in a zone of prospective necrosis from the chick wing bud. Dev. Biol. 18: 553-570.

Gavrieli, Y., Y. Sherman, and S.A. Ben-Sasson. 1992. Identification of programmed cell death in situ via specific labeling of nuclear DNA fragmentation. J. Cell Biol. 119: 493-501.

Gilman, S. and S.W. Newman. 1989. Anatomy of the brain stem: Medulla, pons, and midbrain. In Manter and Gatz's essentials of clinical neuroanatomy and neurophysiology (ed. S. Gilman and S.W. N ewman), pp. 71-85. F.A. Davis Company, Philadel phia, PA.

Graham, A., I. Heyman, and A. Lumsden. 1993. Even-numbered rhombomeres control the apoptotic elimination of neural crest cells from odd-numbered rhombomeres in the chick hindbrain. Development 119: 233-245.

Jeffs, P. and M. Osmond. 1992. A segmented pattern of cell death during development of the chick embryo. Anant. Embryol. 185: 589-598.

Jeffs, P., K. Jaques, and M. Osmond. 1992. Cell death in cranial neural development. A nat. Embryol. 185: 583-588.

Jonk, L.J.C., M.E.J. de Jonge, C.E.G.M. Pals, S. Wissink, J.M.A. Vervaart, J. Schoorlemmer, and W. Kruijer. 1994. Cloning and expression during development of three murine members of the COUP family of nuclear orphan receptors. Mech. Dev. 47: 81-97.

Kahle, W., H. Leonhardt, and W. Platzer. 1993a. Spinal cord and spinal nerve. In Color atlas/text of human anatomy: Nervous system and sensory organs (ed. W. Kahle et al.), pp. 64-67. Thieme Medical Publishers, New York, NY.

- - - 1993b. Brain stem and cranial nerves. In Color atlas/ text of human anatomy: Nervous system and sensory organs. (ed. W. Kahle et al.) pp. 106-111. Thieme M edical Publishers, N ew York, NY.

Kliewer, S.A., U. Kazuhiko, R.A. Heyman, D.J. Mangelsdorf, J.A. Dyck, and R.M. Evans. 1992. Retinoid X receptorCOUP-TF interactions modulate retinoic acid signaling. Proc. Natl. Acad. Sci. 89: 1448-1452.

Ladias, J.A.A. and S.K. Karathanasis. 1991. Regulation of the apolipoprotein AI gene by ARP-1, a novel member of the steroid receptor superfamily. Science 251: 561-565.

Ladias, J.A.A., M. Hadzopoulou-Cladaras, D. Kardassis, P. Cardot, J. Cheng, V. Zannis, and C. Cladaras. 1992. Transcriptional regulation of human apolipoprotein genes $A p o B$, ApoCIII, and ApoAll by members of the steroid hormone receptor superfamily HNF-4, ARP-1, Ear-2, and EAR-3. J. Biol. Chem. 267: 15849-15868.

Lee, J.E., S.M. Hollengerg, L. Snider, D.L. Turner, N. Lipnick, and $\mathrm{H}$. Weintraub. 1995. Conversion of Xenopus ectoderm into neurons by NeuroD, a basic helix-loop-helix protein. Science 268: 836-844.

Leng, X., A.J. Cooney, S.Y. Tsai, and M.-J. T sai. 1996. M olecular mechanisms of COUP-TF-mediated transcriptional repression: Evidence for transrepression and active repression. Mol. Cell. Biol. 16: 2332-2340.

Lumsden, A. 1990. The cellular basis of segmentation in the devel oping hindbrain. Trends Neurosci. 13: 329-335.

Lumsden, A. and R. Keynes. 1989. Segmental patterns of neuronal development in the chick hindbrain. Nature 337: 424428.

Lumsden, A., N. Sprawson, and A. Graham. 1991. Segmental origin and migration of neural crest cells in the hindbrain region of the chick embryo. Development 113: 12811291.

Maden, A., C. Horton, A. Graham, L. Leonard, J. Pizzey, G. Siegenthaler, A. Lumsden, and U. Eriksson. 1992. Domains of cellular retinoic acid-binding protein I (CRABP I) expression in the hindbrain and neural crest of the mouse embryo. Mech. Dev. 37: 13-23.

M ansour, S.L., K.R. Thomas, and M.R. Capecchi . 1988. Disruption of the proto-oncogene int-2 in mouse embryo-derived stem cells: A general stratagy for targeting mutations to nonsel ectable genes. Nature 336: 348-352.

M cM ahon, A.P. and A. Bradley. 1990. The Wnt-1 (int-1) protooncogene is required for devel opment of a large region of the mouse brain. Cell 62: 1073-1085.

Mietus-Snyder, M., F.M. Sladek, G.S. Ginsburg, C.F. Kuo, J.A.A Ladias, J.E. Darnell Jr., and S.K. Karathanasis. 1992. Antagonism between apolipoprotein AI regulatory protein 1, Ear3/ COUP-TF, and hepatocyte nuclear factor 4 modulates apo- 
lipoprotein CIII gene expression in liver and intestinal cells. Mol. Cell. Biol. 12: 1708-1718.

Miyajima, N ., Y. Kadowaki, S. Fukushige, S. Shimizu, K. Semba, Y. Yamanashi, K. Matsubara, K. Toyoshima, and T. Yamamoto. 1988. Identification of two novel members of erbA superfamily by molecular cloning: The gene products of the two are highly related to each other. Nucleic Acids Res. 16: 11057-11074.

Mlodzik, M., Y. Hiromi, U. Weber, C.S. Goodman, and G.M. Rubin. 1990. The Drosophila seven-up gene, a member of the steroid receptor gene superfamily, controls photoreceptor cell fates. Cell 60: 211-224.

Murphy, P. and R.E. Hill. 1991. Expression of the mouse labiallike homeobox-containing genes, Hox 2.9 and Hox 1.6 during segmentation of the hindbrain. Devel opment 111: 61-74.

N aya, F.J., C.M.M. Stellrecht, and M.-J. Tsai. 1995. Tissue-specific regulation of the insulin gene by a novel basic helixloop-helix transcription factor. Genes \& Dev. 9: 1009-1019.

N oden, D.M. 1983. The role of neural crest in patterning of the avian cranial skeletal, connective, and muscle tissues. Dev. Biol. 96: 144-165.

- - - 1988. Interactions and fates of avian craniofacial mesenchyme. Development (Suppl.) 103: 121-140.

Pereira, F.A., Y. Qiu, M.-J. Tsai, and S.Y. T sai. 1994. COUP-TF: Expression during mouse embryogenesis. J. Steroid Biochem. Mol. Biol. 53: 503-508.

Pereira, F.A., Y. Qiu, M.-J. Tsai, and S.Y. Tsai. 1995. COUP-TE: Expression during mouse embryogenesis. J. Steroid Biochem. Mol. Biol. 53: 503-508.

Qiu, Y., A.J. Cooney, S. Kuratani, F.J. DeMayo, S.Y. Tsai, and M.-J. Tsai. 1994a. Spatiotemporal expression patterns of chicken oval bumin upstream promoter-transcription factors in the developing mouse central nervous system: Evidence for a role in segmental patterning of the diencephal on. Proc. Natl. Acad. Sci. 91: 4451-4455.

Qiu, Y., S.Y. Tsai, and M.-J. T sai. 1994b. COUP-TF: An orphan member of the steroid/thyroid hormone receptor superfamily. Trends Endocrinol. Metab. 5: 234-239.

Qiu, Y., V. Krishnan, Z. Zeng, D.J. Gilbert, N.G. Copeland, L. Gibson, T. Yang-Feng, N.A. Jenkins, M.-J. Tsai, and S.Y. Tsai. 1995. Isolation, characterization, and chromosomal Iocalization of mouse and human COUP-TFI and II genes. Ge nomics 29: 240-246.

Ritchie, H.H., L.H. Wang, S.Y. T sai, B. O'M alley, and M .-J. Tsai 1990. COUP-TF gene: A structure unique for the steroid/ thyroid receptor superfamily. Nucleic Acids Res. 18: 68576882.

Robertson, E.J. 1987. Embryo-derived stem cells. In Teratocarcinomas and embryonic stem cells: A practical approach (ed. E.J. Robertson), pp. 71-112. Oxford, N ew York, NY.

Romirez-Solis, R., J. Rivera-Perez, J. Wallace, M. Wims, H. Zheng, and A. Bradley. 1992. Genomic DNA micro-extraction: A method to screen numerous samples. Anal. Biochem. 201: 331-335.

Roskies, A. and D.D.M. O'Leary. 1994. Control of topographis retinal axon branching by inhibitory membrane-bound molecules. Science 265: 799-803.

Ruberte, E., V. Freiderich, G. Marriss-Kay, and P. Chambon. 1992. Differential distribution patterns of CRABP I and CRABP II transcripts during mouse embryogenesis. Development 115: 973-987.

Sato, M., L. Lopez-Mascaraque, C.D. Heffner, and D.D.M. O'Leary. 1994. Action of a diffusible target-derived chemoattractant on cortical axon branch induction and directed growth. Neuron 13: 791-803.

Soriano, P., C. M ontgomery, R. Geske, and A. Brandley. 1991.
Targeted disruption of the c-src proto-oncogene leads to osteropetrosis in mice. Cell 64: 693-702.

Tessier-Lavigne, M. and C.S. Goodman. 1996. The molecular biology of axon guidance. Science 274: 1123-1133.

Trainor, P.A. and P.P.L. Tam. 1995. Cranial paraxial mesoderm and neural crest cells of the mouse embryo: Co-distrubution in the craniofacial mesenchyme but distinct segragation in branchial arches. Development 121: 2569-2582.

Tran, P., X.-K. Zhang, G. Sal bert, T. Hermann, J.M. Lehmann, and M. Pfahl. 1992. COUP orphan receptors are negative regulators of retinoic acid response pathways. Mol. Cell. Biol. 12: 4666-4676.

Tsai, S.Y. and M.--J. T sai. 1997. Chick oval bumin upstream promoter-transcription factors (COU P-TFs): Coming of age. Endobrine Rev. 18: 229-240.

Wall, N .A., C.M. Jone, B.L.M. Hogan, and C.V.E. Wright. 1992. Expression and modification of hox-2.1 protein in mouse embryos. Mech. Dev. 37: 111-120.

Wang, L.H., S.Y. Tsai, R.G. Cook, W.G. Beattie, M.-J. Tsai, and B.W. O'Malley. 1989. COUP transcription factor is a member of the steroid receptor superfamily. Nature 340: 163-166.

Wang, L.H., N.H. Ing, S.Y. Tsai, B.W. O'M alley, and M.-J. Tsai. 1991. The COUP-TFs compose a family of functionally related transcription factors. Gene Expression 1: 207-216.

Wilkinson, D.G. and R. Krumbauf. 1990. Molecular approaches to the segmentation of the hindbrain. Trends Neurosci. 13: 335-339.

Wilkinson, D.G. 1992. Whole mount in situ hybridization of vertebrate embryos. In In situ hybridization: A practical approach (ed. D.G. Wilkinson), pp. 75-83. Oxford University Press, New York, NY.

-_- 1993. M olecular mechanisms of segmental patterning in the vertebrate hindbrain and neural crest. BioEssays 15: 499-505.

Wilkinson, D.G., S. Bhatt, P. Chavrier, R. Bravo, and P. Charnay. 1989. Segment-specific expression of a zinc-finger gene in the developing nervous system of the mouse. Nature 337: 461-464. 


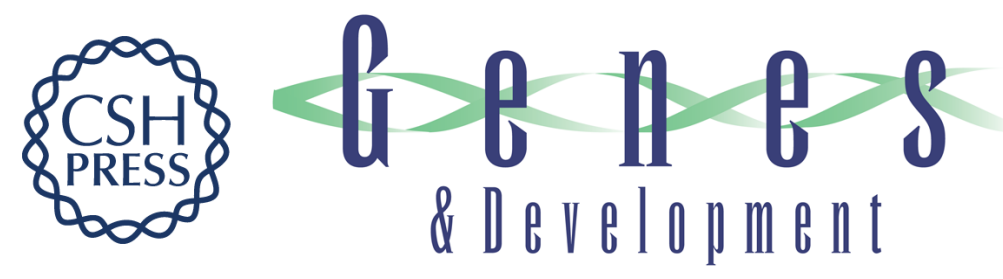

\section{Null mutation of mCOUP-TFI results in defects in morphogenesis of the glossopharyngeal ganglion, axonal projection, and arborization}

Yuhong Qiu, Fred A. Pereira, Francesco J. DeMayo, et al.

Genes Dev. 1997, 11:

Access the most recent version at doi:10.1101/gad.11.15.1925

References This article cites 51 articles, 21 of which can be accessed free at: http://genesdev.cshlp.org/content/11/15/1925.full.html\#ref-list-1

License

Email Alerting

Receive free email alerts when new articles cite this article - sign up in the box at the top Service right corner of the article or click here.

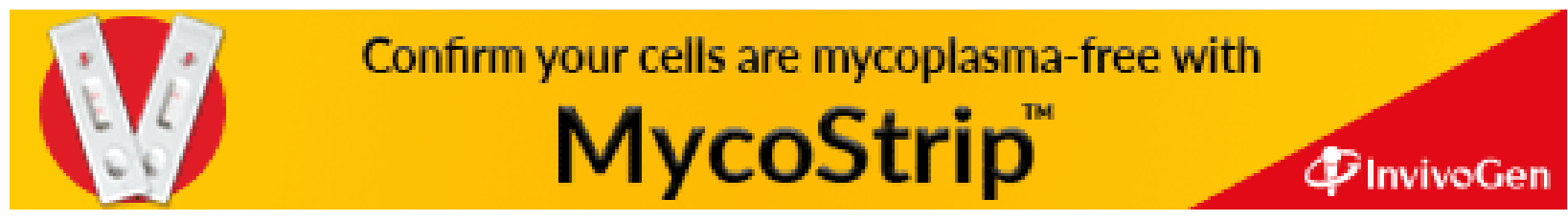

